\title{
Impact of Nutritional Assessment on the Clinical Outcomes of Patients with Non-albicans Candidemia: A Multicenter Study
}

\author{
Yi-Chien Lee ${ }^{1,2}$, Yong-Chen Chen ${ }^{2,3}$, Jann-Tay Wang ${ }^{4,5}$, Fu-Der Wang ${ }^{6,7}$, Min-Han Hsieh ${ }^{8}$, Ing-Moi Hii ${ }^{9}$, \\ Yu-Lin Lee ${ }^{9}$, Mao-Wang Ho ${ }^{10}$, Chun-Eng Liu ${ }^{9}$, Yen-Hsu Chen ${ }^{8}{ }^{(1)}$ and Wei-Lun Liu ${ }^{2,11, *(0)}$
}

1 Department of Internal Medicine, Fu Jen Catholic University Hospital, Fu Jen Catholic University, New Taipei City 243, Taiwan; cimedin7@yahoo.com.tw

2 School of Medicine, College of Medicine, Fu Jen Catholic University, New Taipei City 242, Taiwan; yongchenchen0824@gmail.com

3 Master Program of Big Data in Biomedicine, College of Medicine, Fu Jen Catholic University, New Taipei City 242, Taiwan

4 Department of Internal Medicine, National Taiwan University Hospital, Taipei 100, Taiwan; 14bcr@yahoo.com.tw

5 Institute of Infectious Diseases and Vaccinology, National Health Research Institutes, Tsu-Nan County 350, Taiwan

6 Division of Infectious Diseases, Department of Internal Medicine, Taipei Veterans General Hospital, Taipei 112, Taiwan; fdwang@vghtpe.gov.tw

7 School of Medicine, National Yang-Ming University, Taipei 112, Taiwan

8 Division of Infectious Diseases, Department of Internal Medicine, Kaohsiung Medical University Hospital, Kaohsiung Medical University, Kaohsiung 807, Taiwan; 970388kmuh@gmail.com (M.-H.H.);

updates

Citation: Lee, Y.-C.; Chen, Y.-C.; Wang, J.-T.; Wang, F.-D.; Hsieh, M.-H.; Hii, I.-M.; Lee, Y.-L.; Ho, M.-W.; Liu, C.-E.; Chen, Y.-H.; et al. Impact of Nutritional Assessment on the Clinical Outcomes of Patients with Non-albicans Candidemia:

A Multicenter Study. Nutrients 2021, 13, 3218. https://doi.org/10.3390/ nu13093218

Academic Editor: Jose Lara

Received: 14 August 2021

Accepted: 14 September 2021

Published: 16 September 2021

Publisher's Note: MDPI stays neutral with regard to jurisdictional claims in published maps and institutional affiliations.

Copyright: (c) 2021 by the authors. Licensee MDPI, Basel, Switzerland. This article is an open access article distributed under the terms and conditions of the Creative Commons Attribution (CC BY) license (https:// creativecommons.org/licenses/by/ $4.0 /)$. d810070@kmu.edu.tw (Y.-H.C.)

9 Division of Infectious Diseases, Department of Internal Medicine, Changhua Christian Hospital, Changhua 500, Taiwan; 131624@cch.org.tw (I.-M.H.); leeyulin@gmail.com (Y.-L.L.); chuneng@cch.org.tw (C.-E.L.)

10 Division of Infectious Diseases, Department of Internal Medicine, China Medical University Hospital, Taichung 404, Taiwan; cmchid@yahoo.com.tw

11 Division of Critical Care Medicine, Department of Emergency \& Critical Care Medicine, Fu Jen Catholic University Hospital, Fu Jen Catholic University, New Taipei City 243, Taiwan

* Correspondence: medrpeterliu@gmail.com; Tel.: +88-62-8512-8888 (ext. 22200)

Abstract: Several studies have demonstrated that malnutrition is a negative prognostic factor for clinical outcomes. However, there is limited evidence for the effect of malnutrition on clinical outcomes in patients with candidemia. We investigated the relationship between malnutrition and all-cause 28-day mortality among patients with non-albicans candidemia. Between July 2011 and June 2014, all adult patients with non-albicans candidemia, including C. tropicalis, C. glabrata, C. parapsilosis and so on, were enrolled. The Malnutrition Universal Screening Tool (MUST) scores were used to determine the patients' nutritional status before the onset of candidemia. A total of 378 patients were enrolled; $43.4 \%$ developed septic shock and $57.1 \%$ had a high risk of malnutrition (MUST $\geq 2$ ). The all-cause 28 -day mortality rate was $40.7 \%$. The Cox proportional hazards model revealed that C. tropicalis (HR, 2.01; 95\% CI, 1.24-3.26; $p=0.005)$, Charlson comorbidity index (HR, 1.10; 95\% CI, $1.03-1.18 ; p=0.007)$, Foley catheter use (HR, 1.68; 95\% CI, 1.21-1.35; $p=0.002)$, concomitant bacterial infections (HR, 1.55; 95\% CI, 1.11-2.17; $p=0.010)$, low platelet count (HR, 3.81; 95\% CI, 2.45-5.91; $p<0.001$ ), not receiving antifungals initially (HR, 4.73; 95\% CI, 3.07-7.29; $p<0.001$ ), and MUST $\geq 2$ (HR, 1.54; 95\% CI, 1.09-2.17; $p=0.014$ ) were independently associated with all-cause 28-day mortality. A simple screening tool for nutritional assessment should be used for patients with non-albicans candidemia to detect early clinical deterioration, and a tailored nutritional care plan should be established for malnourished individuals, to improve their clinical outcomes.

Keywords: nutritional assessment; non-albicans candidemia; MUST 


\section{Introduction}

Candida, one of the most frequently encountered invasive fungal infections in humans, causes a wide spectrum of clinical manifestations, including candidemia, intra-abdominal infections, and osteomyelitis [1]. Candidemia usually leads to longer hospital stay, increased medical costs, substantial complications, and all-cause in-hospital mortality of up to $30-60 \%$ [2,3]. Candida albicans remains the leading cause of candidemia, but nonalbicans candidemia has progressively increased worldwide in recent years, with a varying distribution of species between different countries, particularly in the Asia-Pacific regions [4-6]. Due to the high mortality rate of patients with candidemia, the presence of septic shock [7-12], need for mechanical ventilation [7], severe underlying diseases [7,11], multiple organ failure [8], aging [11], concomitant bacterial infections [12], and inappropriate initiation of antifungal agents [9] were found to be independent risk factors associated with mortality in various studies. Furthermore, different fatality rates have been observed based on different Candida species, and it seems that patients with non-albicans candidemia have a worse prognosis [13].

Universally, malnutrition is a key topic: its prevalence is as high as $37.8-78.1 \%$ in critically ill patients [14], and around $20-50 \%$ of hospitalized patients are diagnosed with undernutrition upon admission [15]. Several prior studies have validated the association between poor nutritional status and adverse clinical outcomes among patients receiving intensive care [14-17], particularly those with candidemia [18]. Different nutrition assessment and screening tools have been used in the previous studies, including Subjective Global Assessment [19], Mini Nutritional Assessment [20], Nutrition Risk Screening-2002 (NRS-2002) [21], and Malnutrition Universal Screening Tool (MUST) [22]. MUST, the foundation for the NRS-2002, was established to recognize individuals with malnourishment in all healthcare settings. It had three components: calculation of the body mass index (BMI) as well as recording of the percentage of unintentional weight loss in the past months and the presence of acute sickness with a reduction in nutritional intake for days [22]. Limited research has been done on the influence of malnourishment on the clinical outcomes of patients with non-albicans candidemia. This study aimed to compare the clinical characteristics of non-albicans candidemic patients with a high risk of malnutrition to those of patients without a high risk and antifungal susceptibility, and to identify the predictors of all-cause 28-day mortality among patients with non-albicans candidemia.

\section{Materials and Methods}

\subsection{Study Design and Settings}

We conducted a retrospective multicenter observational study at five tertiary hospitals, including Taipei Veterans General Hospital in northern Taiwan, China Medical University Hospital and Changhua Christian Hospital in central Taiwan, Chi Mei Medical Center, Liouying Branch, and Kaohsiung Medical University Hospital in southern Taiwan, between 1 July 2011 and 30 June 2014. All adult patients aged over 20years with positive blood cultures for non-albicans Candida species admitted to any of the five participating hospitals were eligible for enrollment. Only the first episode of non-albicans candidemia was analyzed in patients who developed two or more episodes of candidemia during the study period. Individuals with two or more non-albicans Candida species isolated from blood cultures were excluded. A standardized case report form was used to collect information on the demographics and clinical characteristics, including the age, sex, source of candidemia, Charlson comorbidity index, risk factors (receiving chemotherapy, total parenteral nutrition (TPN), use of central venous catheters, recent abdominal surgery, steroids), disease severity (septic shock and receiving intensive care), concomitant bacterial infections, laboratory data, BMI, initial antifungal treatment, and 28-day mortality. The study was approved by the medical ethics committees of the five participating hospitals, and all clinical investigations were performed following the guidelines of the Declaration of Helsinki. 


\subsection{Definitions}

Candidemia was confirmed by the isolation of non-albicans Candida species in at least one set of blood cultures among patients with corresponding clinical symptoms/signs of infection [23]. The origin of the candidemia was determined based on clinical manifestations, microbiological findings, and radiological investigations. Catheter-related bloodstream infection (CRBSI) was defined by the same organism being isolated from the indwelling catheter segment with the growth of $\geq 15$ colony-forming units via semi-quantitative tip culture and peripheral blood culture [24]. If no apparent focus of the infection was identified at other sites, candidemia was classified as primary [23]. Septic shock was diagnosed when a patient had either systolic blood pressure $\leq 90 \mathrm{mmHg}$ or mean arterial pressure $\leq 70 \mathrm{mmHg}$ accompanied by the use of vasopressors. A concomitant bacterial infection was defined as a bacterial infection occurring within seven days prior to the first episode of the candidemia. Use of steroids was defined as a prescription of at least $10 \mathrm{mg}$ prednisolone or an equivalent daily dosage for more than one week within 30 days before candidemia [25]. The initial antifungal treatment was the first prescribed antifungal agent, while invasive fungemia was clinically suspected. All-cause 28-day mortality was recorded when a patient died from any cause during hospitalization.

\subsection{Mycological Diagnosis of Candidemia and Antifungal Susceptibility Testing}

Fungal blood cultures were processed using the BACTEC culture system (Becton Dickinson Microbiology System, Sparks, MD, USA). All non-albicans Candida isolates were identified to the species level by morphology analysis on CHROMagar (Creative Life Science, Ltd., New Taipei City, Taiwan) and biochemical methods using the API ID 32C system (bioMérieux, Marcy l'Etoile, France) or Vitek 2 system (bioMérieux, Marcy l'Etoile, France) according to the regulations of each participating hospital. The in vitro susceptibility to nine antifungal agents, including anidulafungin, caspofungin, micafungin, fluconazole, voriconazole, itraconazole, posaconazole, 5-fluocytosine, and amphotericin B, was determined using the broth microdilution method with the Sensititre YeastOne system (Trek Diagnostic Systems, Ltd., East Grinstead, UK) according to the manufacturer's instructions. We utilized C. krusei (ATCC 6258) and C. parapsilosis (ATCC 22019) as reference isolates for quality control. The minimal inhibitory concentrations (MICs) of the nine tested antifungal agents were interpreted using the clinical breakpoints or epidemiological cut-off values proposed by the Clinical and Laboratory Standard Institute (CLSI) recommendations [26].

\subsection{Nutrition Assessment}

All patients with non-albicans candidemia underwent nutritional assessment via measurement of MUST scores before the onset of candidemia. The information needed for the MUST was provided by either the patients or their caregivers. As described before, the MUST methodology comprised three independent parameters: BMI score (BMI $>20=0$, BMI 18.5-20 = 1, BMI < $18.5=2$ ); percentage of unexpected weight loss in the past 3-6 months (weight loss $<5 \%=0$, weight loss $5-10 \%=1$, weight loss $>10 \%=2$ ); acute disease effect score (a score of 2 was added if the patient was acutely ill with subsequent lack of any dietary intake for more than five days). Based on the total scores calculated, the development of malnourishment was determined as low (total score $=0$ ), medium (total score $=1$ ), and high risk (total scores $\geq 2$ ). We further classified MUST into a dichotomized group (low to medium risk of malnutrition 0 or 1 (non-high-risk group), versus high risk of malnutrition $\geq 2$ (high-risk group)). The MUST score was selected as the evaluation tool for this study because of its good predictive value for clinical outcomes in a variety of patient populations [27-29].

\subsection{Statistical Analyses}

Descriptive data for quantitative variables were expressed as mean \pm standard deviation and analyzed using Student's $t$-test or Mann-Whitney U test. Categorical variables were presented as counts (\%) and compared using the chi-squared test or Fisher's exact 
test. Statistical significance was determined using two-tailed tests, and a $p$-value $<0.05$ was considered as the threshold for statistical significance. To identify the independent predictors of all-cause 28-day mortality, a Cox proportional hazards model in a stepwise approach was used to calculate the hazard ratios and corresponding $95 \%$ confidence intervals. Survival was plotted using Kaplan-Meier curves, and differences were evaluated using the log-rank test. All statistical analyses were conducted using SAS statistical software (version 9.4; SAS Institute, Cary, NC, USA).

\section{Results}

Initially, 597 patients with a diagnosis of non-albicans candidemia were recruited, but 219 patients were excluded because of missing clinical data, including 205 with incomplete MUST scores, 12 with incorrect sampling, and two that were transferred to another hospital. Finally, 378 patients were enrolled in this study, and 146 (38.6\%) were infected with C. tropicalis, $133(35.2 \%)$ with C. glabrata, 78 (20.6\%) with C. parapsilosis, $21(5.6 \%)$ with other Candida species, including C. guilliermondii (8, 2.1\%), C. krusei $(4,1.1 \%)$, C. lusitaniae $(2,0.5 \%)$, C. lipolytica $(2,0.5 \%)$, C. intermedia $(1,0.3 \%)$, C. catenulate $(1,0.3 \%)$, C. metapsilosis $(1,0.3 \%)$, C. pulcherrima $(1,0.3 \%)$, and C. sake $(1,0.3 \%)$ (Figure 1$)$.

Patients diagnosed with non-albians candidemia $(n=597)$

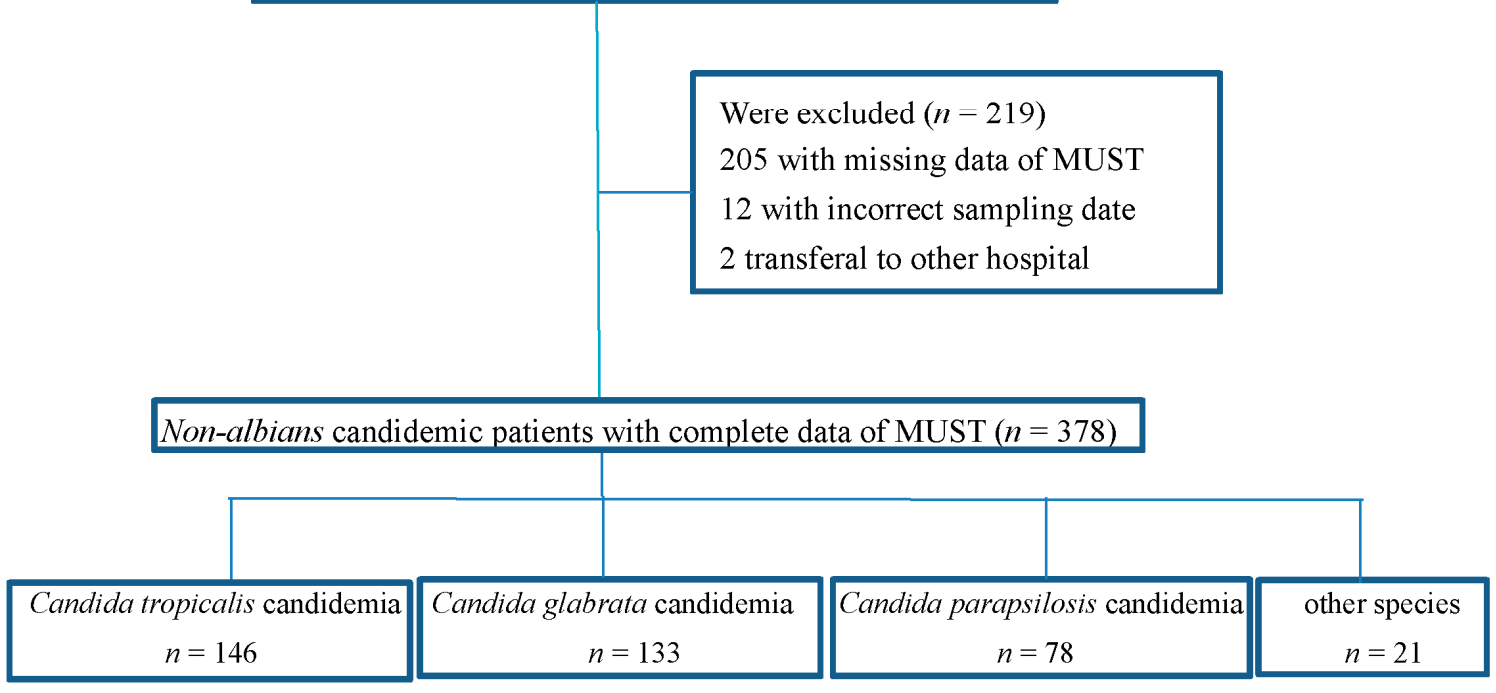

Figure 1. Flow chart of patients with non-albicans candidemia included in the analysis.

Among these patients, more than $60 \%$ were men, and their mean \pm standard deviation of age was $66 \pm 17$ years (Table 1). The three leading origins of candidemia were the central venous catheter, primary infection, and an intra-abdominal focus. The predominant nonalbicans Candida species was C. tropicalis (38.6\%). More than two-fifths $(43.4 \%)$ of the patients developed septic shock due to candidemia, and the mean \pm standard deviation of the Charlson comorbidity score was $4.2 \pm 2.5$. Previous use of steroids was the most common precipitating factor associated with non-albicans candidemia, and approximately half $(47.4 \%)$ of all the patients were found to have concomitant bacterial infections. The majority $(71.2 \%)$ of the participants were prescribed fluconazole initially, and the all-cause 28 -day mortality rate in this study was $40.7 \%$. 
Table 1. Comparison of demographics and clinical characteristics of candidemic patients with MUST $\geq 2$ and $<2$.

\begin{tabular}{|c|c|c|c|c|}
\hline & All, \% & MUST $\geq 2$ & MUST < 2 & $p$ \\
\hline & $(n=378)$ & $(n=216)$ & $(n=162)$ & \\
\hline Age & $66.13 \pm 16.88$ & $65.76 \pm 16.79$ & $66.63 \pm 17.04$ & 0.62 \\
\hline Gender (male) & $235(62.2)$ & $137(63.4)$ & $98(60.5)$ & 0.560 \\
\hline Source of candidemia & & & & $<0.001$ \\
\hline Primary & $89(23.5)$ & $33(15.3)$ & $56(34.6)$ & \\
\hline Central catheter & $100(26.5)$ & $57(26.4)$ & $43(26.5)$ & \\
\hline Urinary tract & $56(14.8)$ & $38(17.6)$ & $18(11.1)$ & \\
\hline Respiratory tract & $61(16.1)$ & $39(18.1)$ & $22(16.2)$ & \\
\hline Intra-abdomen & $65(17.2)$ & $47(21.8)$ & $18(11.1)$ & \\
\hline Wound & $4(1.1)$ & $1(0.5)$ & $3(1.9)$ & \\
\hline Candida species & & & & 0.01 \\
\hline C. tropicalis & $146(38.6)$ & $89(41.2)$ & $57(35.2)$ & \\
\hline C. glabrata & $133(35.2)$ & $82(38.0)$ & $51(31.5)$ & \\
\hline C. parapsilosis & $78(20.6)$ & $33(15.3)$ & $45(27.8)$ & \\
\hline Others & $21(5.6)$ & & & \\
\hline Charlson comorbidity index & $4.23 \pm 2.48$ & $4.19 \pm 2.47$ & $4.29 \pm 2.49$ & 0.73 \\
\hline Candida colonization & $133(35.2)$ & $84(38.9)$ & $49(30.2)$ & 0.08 \\
\hline Receiving chemotherapy & $106(28.0)$ & $59(27.3)$ & $47(29.0)$ & 0.72 \\
\hline TPN use & $82(21.7)$ & $57(26.4)$ & $25(15.4)$ & 0.01 \\
\hline Use of venous access & $267(70.6)$ & $160(74.1)$ & $107(66.0)$ & 0.09 \\
\hline Foley use & $170(45.0)$ & $100(46.3)$ & $70(43.2)$ & 0.55 \\
\hline Recent abdominal surgery & $63(16.7)$ & $43(19.9)$ & $20(12.3)$ & 0.05 \\
\hline Use of steroids & $309(81.7)$ & $174(80.6)$ & $135(83.3)$ & 0.49 \\
\hline $\begin{array}{l}\text { Concomitant bacterial } \\
\text { infection }\end{array}$ & $179(47.4)$ & $114(52.8)$ & $65(40.1)$ & 0.01 \\
\hline $\mathrm{WBC}(/ \mu \mathrm{L})$ & & & & 0.35 \\
\hline$<6700$ & $125(33.1)$ & $65(30.1)$ & $60(37.0)$ & \\
\hline$\geq 6700$ and $<12,100$ & $124(32.8)$ & $73(33.8)$ & $51(31.5)$ & \\
\hline$\geq 12,100$ & $129(34.1)$ & $78(36.1)$ & $51(31.5)$ & \\
\hline $\mathrm{Hb}<10 \mathrm{mg} / \mathrm{dl}$ & $209(55.3)$ & $115(53.2)$ & $94(58.0)$ & 0.35 \\
\hline Platelet $(/ \mu \mathrm{L})$ & & & & 0.15 \\
\hline$<79,000$ & $133(35.2)$ & $67(31.0)$ & $66(40.7)$ & \\
\hline$\geq 79,000$ and $<185,000$ & $120(31.7)$ & $73(33.8)$ & $47(29.0)$ & \\
\hline$\geq 185,000$ & $125(33.1)$ & $76(35.2)$ & $49(30.2)$ & \\
\hline ICU admission & $61(15.1)$ & $39(18.1)$ & $22(13.6)$ & 0.24 \\
\hline BMI & $21.96 \pm 4.57$ & $20.45 \pm 4.41$ & $23.98 \pm 3.98$ & $<0.001$ \\
\hline Septic shock & $164(43.4)$ & $106(65.4)$ & $58(35.8)$ & 0.01 \\
\hline Antifungal therapy & & & & 0.19 \\
\hline Initial use of fluconazole & $269(71.2)$ & $157(72.7)$ & $112(69.1)$ & \\
\hline Initial use of echinocandin & $65(17.2)$ & $31(14.4)$ & $34(21.0)$ & \\
\hline None & $44(11.6)$ & $28(12.3)$ & $16(9.9)$ & \\
\hline Death within 28 days & $154(40.7)$ & $97(59.9)$ & $57(35.2)$ & 0.06 \\
\hline
\end{tabular}

The in vitro susceptibilities of the 304 non-albicans Candida isolates to the nine tested antifungal agents are summarized in Table 2. All three echinocandins exhibited excellent sensitivity against these strains (>95\%), except for caspofungin against C. glabrata isolates $(91.8 \%)$, indicating that echinocandins remain the drug of choice for treating non-albicans candidemia. However, the echinocandin $\mathrm{MIC}_{50}$ and $\mathrm{MIC}_{90}$ of C. parapsilosis (0.5-1 and $0.5-2 \mathrm{mg} / \mathrm{L}$, respectively) were higher than those of the other non-albicans Candida species. The overall fluconazole-resistance rate among all non-albicans Candida isolates was 10.2\% (31), including 25 in C. tropicalis, four in C. glabrata, and two in C. parapsilosis. Moreover, C. glabrata displayed higher fluconazole $\mathrm{MIC}_{50}$ and $\mathrm{MIC}_{90}(16 \mathrm{mg} / \mathrm{L}$ and $32 \mathrm{mg} / \mathrm{L}$, respectively), and the highest resistance rate to fluconazole was observed in $C$. tropicalis $(17.1 \%)$. The voriconazole-resistance rates in C. tropicalis and C. parapsilosis were $15.1 \%$ and $2.1 \%$, respectively. 
Table 2. In vitro susceptibility of antifungal agents among 304 non-albicans Candida isolates.

\begin{tabular}{|c|c|c|c|c|c|c|c|}
\hline \multirow{2}{*}{ Species } & \multirow{2}{*}{ Antifungal Agent } & \multicolumn{3}{|c|}{ MIC (mg/L) } & \multicolumn{3}{|c|}{ Susceptibility, No. (\%) } \\
\hline & & Range & $\mathrm{MIC}_{50}$ & $\mathrm{MIC}_{90}$ & $S$ & SDD & $R(I+R)$ \\
\hline \multirow{9}{*}{$\begin{array}{l}\text { C. tropicalis } \\
(n=146)\end{array}$} & Anidulafungin & $0.03-1$ & 0.12 & 0.25 & $142(97.3)$ & - & $3(2.1)$ \\
\hline & Caspofungin & $0.015->8$ & 0.12 & 0.25 & $141(96.6)$ & - & $5(3.4)$ \\
\hline & Micafungin & $0.015-2$ & 0.03 & 0.03 & $142(97.3)$ & - & $4(2.7)$ \\
\hline & Fluconazole & $0.25->256$ & 2 & 16 & $94(64.4)$ & $27(18.5)$ & $25(17.1)$ \\
\hline & Voriconazole & $0.015->8$ & 0.25 & 2 & $65(44.5)$ & $59(40.4)$ & $22(15.1)$ \\
\hline & Itraconazole & $0.06-1$ & 0.25 & 0.5 & - & - & - \\
\hline & Posaconazole & $0.015-1$ & 0.25 & 0.5 & - & - & - \\
\hline & Flucytosine & $\leq 0.06->64$ & $\leq 0.06$ & 0.12 & - & - & - \\
\hline & Amphotericin B & $\leq 0.12-2$ & 0.5 & 1 & - & - & - \\
\hline \multirow{9}{*}{$\begin{array}{l}\text { C. glabrata } \\
(n=110)\end{array}$} & Anidulafungin & $0.03-1$ & 0.06 & 0.12 & $109(99.1)$ & - & $1(0.9)$ \\
\hline & Caspofungin & $0.03-1$ & 0.12 & 0.12 & $101(91.8)$ & & $9(8.2)$ \\
\hline & Micafungin & $\leq 0.008-1$ & 0.015 & 0.015 & $108(98.2)$ & & $2(1.8)$ \\
\hline & Fluconazole & $0.5->256$ & 16 & 32 & - & $106(96.4)$ & $4(3.6)$ \\
\hline & Voriconazole & $\leq 0.008-4$ & 0.5 & 0.5 & - & - & - \\
\hline & Itraconazole & $\leq 0.015-4$ & 0.5 & 1 & - & - & - \\
\hline & Posaconazole & $\leq 0.008->8$ & 1 & 2 & - & - & - \\
\hline & Flucytosine & $\leq 0.06-0.5$ & $\leq 0.06$ & $\leq 0.06$ & - & - & - \\
\hline & Amphotericin B & $\leq 0.12-4$ & 0.5 & 1 & - & - & - \\
\hline \multirow{9}{*}{$\begin{array}{l}\text { C. parapsilosis } \\
(n=48)\end{array}$} & Anidulafungin & $0.25-2$ & 1 & 2 & $48(100)$ & $0(0)$ & $0(0)$ \\
\hline & Caspofungin & $0.25-1$ & 0.5 & 0.5 & $48(100)$ & $0(0)$ & $0(0)$ \\
\hline & Micafungin & $0.25-2$ & 1 & 2 & $48(100)$ & $0(0)$ & $0(0)$ \\
\hline & Fluconazole & $0.25-16$ & 1 & 2 & $45(93.8)$ & $1(2.1)$ & $2(4.2)$ \\
\hline & Voriconazole & $\leq 0.008-0.5$ & 0.015 & 0.06 & $46(95.8)$ & $1(2.1)$ & $1(2.1)$ \\
\hline & Itraconazole & $0.03-1$ & 0.12 & 0.12 & - & - & - \\
\hline & Posaconazole & $0.015-1$ & 0.03 & 0.06 & - & - & - \\
\hline & Flucytosine & $\leq 0.06-0.5$ & 0.12 & 0.25 & - & - & - \\
\hline & Amphotericin B & $\leq 0.12-1$ & 0.5 & 0.5 & - & - & - \\
\hline
\end{tabular}

The comparisons of the demographics, laboratory data, and clinical outcomes between the high-risk and non-high-risk groups are also illustrated in Table 1. Half of the patients $(57.1 \%)$ belonged to the group with a high risk of malnutrition, and the mean age and sex distribution were not different between the two groups. More primary candidemia and catheter-associated sources were found in the non-high-risk group, but the focus of candidemia being the urinary tract, respiratory tract, and intra-abdominal region was more frequently observed in the high-risk group. The patients who acquired infections caused by the three predominant types of the non-albicans Candida species were significantly different between the two groups. A higher proportion of patients in the high-risk group presented with septic shock (65.4\% vs. $35.8 \%, p=0.01)$, but the Charlson comorbidity index score was similar between the two groups. As for the risk factors related to candidemia, only TPN use was much more commonly encountered in high-risk patients, with significant differences. Furthermore, patients at high risk for malnutrition tended to have concomitant bacterial infections. Laboratory parameters did not differ between the two groups, except for a higher platelet count observed in the high-risk group. ICU admission and all-cause 28-day mortality were not different between the two groups, although a slightly higher percentage of patients at high risk for malnutrition died than that of the non-high-risk patients, without a significant difference $(59.9 \%$ vs. $35.2 \%, p=0.06)$. We further explored the 28 -day survival probability of high-risk versus non-high-risk patients acquiring non-albicans candidemia, and there was a trend that the former had a higher mortality rate when compared to the latter, as shown in Figure $2(p=0.08)$. 


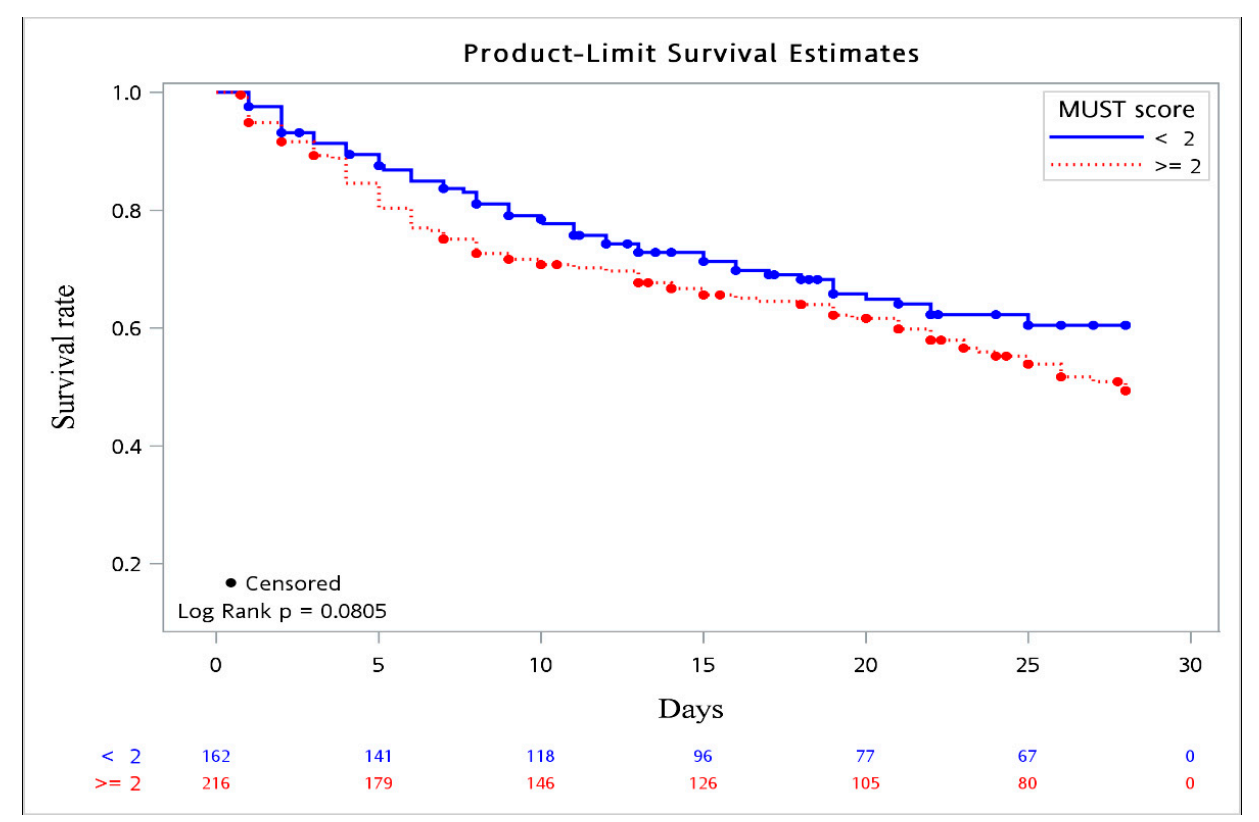

Figure 2. Kaplan-Meier survival curve. Survival probability based on MUST score ( $\geq 2$ vs. $<2)$.

To verify the importance of nutrition assessment on the clinical outcomes of patients with non-albicans candidemia, a Cox proportional hazards model in a stepwise approach was performed using specific identified factors (Table 3). The source of the candidemia, C. tropicalis, Candida colonization, Foley catheter use, concomitant bacterial infections, lower haemoglobin level, thrombocytopenia, ICU admission, septic shock, and no antifungal therapy initially were all associated with all-cause 28-day mortality in patients with nonalbicans candidemia. After adjustment for confounders, C. tropicalis (HR, 2.01; 95\% CI, 1.24-3.26; $p=0.005$ ), Charlson comorbidity index (HR, 1.10; 95\% CI, 1.03-1.18; $p=0.007$ ), Foley catheter use (HR, 1.68; 95\% CI, 1.21-1.35; $p=0.002)$, concomitant bacterial infections (HR, 1.55; 95\% CI, 1.11-2.17; $p=0.010)$, low platelet count (HR, 3.81; 95\% CI, 2.45-5.91; $p<0.001$ ), not receiving antifungals initially (HR, 4.73; 95\% CI, 3.07-7.29; $p<0.001$ ), and MUST $\geq 2$ (HR, 1.54; 95\% CI, 1.09-2.17; $p=0.014)$ were recognized as independent predictors of a higher risk of all-cause 28-day mortality.

Table 3. Predictors associated with 28-day mortality among patients with non-albicans candidemia.

\begin{tabular}{|c|c|c|c|c|}
\hline Variables & Unadjusted HR & $p$-Value & Adjusted HR & $p$-Value \\
\hline & $(95 \% \mathrm{CI})$ & & $(95 \% \mathrm{CI})$ & \\
\hline Age & $1.00(0.99-1.01)$ & 0.943 & & \\
\hline Gender, male & $1.24(0.89-1.73)$ & 0.208 & & \\
\hline \multicolumn{5}{|l|}{ Source of candidemia } \\
\hline Primary & & Reference & & \\
\hline Central catheter & $2.35(1.42-3.89)$ & 0.001 & & \\
\hline Urinary tract & $1.10(0.15-8.16)$ & 0.925 & & \\
\hline Respiratory tract & $1.96(1.10-3.50)$ & 0.022 & & \\
\hline Intra-abdomen & $2.19(1.26-3.81)$ & 0.005 & & \\
\hline Wound & $2.43(1.43-4.12)$ & 0.001 & & \\
\hline \multicolumn{5}{|l|}{ Candida species } \\
\hline C. parapsilosis & & Reference & & Reference \\
\hline C. tropicalis & $2.36(1.47-3.79)$ & $<0.001$ & $1.83(1.12-2.97)$ & 0.015 \\
\hline C. glabrata & $1.30(0.79-2.16)$ & 0.305 & $0.92(0.55-1.56)$ & 0.766 \\
\hline Others & $1.20(0.51-2.80)$ & 0.681 & $1.09(0.46-2.60)$ & 0.839 \\
\hline Charlson comorbidity index & 1.07 (1.00-1.14) & 0.052 & $1.08(1.01-1.16)$ & 0.020 \\
\hline Candida colonization & $1.38(1.00-1.90)$ & 0.048 & & \\
\hline
\end{tabular}


Table 3. Cont.

\begin{tabular}{|c|c|c|c|c|}
\hline Variables & Unadjusted HR & $p$-Value & Adjusted HR & $p$-Value \\
\hline & $(95 \% \mathrm{CI})$ & & $(95 \% \mathrm{CI})$ & \\
\hline Receiving chemotherapy & $0.79(0.55-1.15)$ & 0.222 & & \\
\hline TPN use & $0.93(0.64-1.35)$ & 0.687 & & \\
\hline Use of venous access & $1.12(0.79-1.60)$ & 0.535 & & \\
\hline Foley use & $1.65(1.20-2.26)$ & 0.002 & $1.67(1.19-2.35)$ & 0.003 \\
\hline Recent abdominal surgery & $0.94(0.62-1.43)$ & 0.775 & & \\
\hline Use of steroids & $1.39(0.88-2.20)$ & 0.161 & & \\
\hline Concomitant bacterial infection & $1.60(1.16-2.20)$ & 0.004 & $1.49(1.06-2.08)$ & 0.021 \\
\hline \multicolumn{5}{|l|}{$\mathrm{WBC}(/ \mu \mathrm{L})$} \\
\hline$<6700$ & & Reference & & \\
\hline$\geq 6700$ and $<12,100$ & $0.74(0.50-1.11)$ & 0.143 & & \\
\hline$\geq 12,100$ & $0.93(0.64-1.36)$ & 0.722 & & \\
\hline $\mathrm{Hb}<10 \mathrm{mg} / \mathrm{dL}$ & $1.54(1.11-2.15)$ & 0.010 & & \\
\hline \multicolumn{5}{|l|}{ Platelet $(/ \mu \mathrm{L})$} \\
\hline$<79,000$ & $3.70(2.41-5.69)$ & $<0.001$ & $3.98(2.56-6.19)$ & $<0.001$ \\
\hline$\geq 79,000$ and $<185,000$ & $1.72(1.07-2.76)$ & 0.025 & $1.58(0.97-2.55)$ & 0.064 \\
\hline$\geq 185,000$ & & Reference & & Reference \\
\hline ICU admission & $1.48(1.01-2.18)$ & 0.045 & & \\
\hline BMI & $1.00(0.96-1.03)$ & 0.780 & & \\
\hline Septic shock & $2.06(1.49-2.84)$ & $<0.001$ & & \\
\hline \multicolumn{5}{|l|}{ Antifungal therapy } \\
\hline Initial use of fluconazole & & Reference & & Reference \\
\hline Initial use of echinocandin & $1.02(0.65-1.59)$ & 0.927 & $1.02(0.65-1.61)$ & 0.932 \\
\hline None & $4.94(3.25-7.51)$ & $<0.001$ & $4.73(3.07-7.29)$ & $<0.001$ \\
\hline MUST $\geq 2$ & $1.33(0.96-1.85)$ & 0.085 & $1.46(1.03-2.07)$ & 0.034 \\
\hline
\end{tabular}

\section{Discussion}

An increasing number of studies have demonstrated that non-albicans Candida has played an increasingly clinical role in the recent decades [4-6,30,31]. Additionally, malnutrition might predict a poorer prognosis in critically ill patients, including patients with candidemia [18]. To the best of our knowledge, this is the first study to authenticate the risk factors for all-cause 28-day mortality among non-albicans candidemic individuals and the impact of undernutrition on clinical outcomes. In the present study, the majority of the non-albicans Candida species were C. tropicalis, and $43.4 \%$ of the patients developed septic shock with an all-cause 28-day mortality rate of $40.7 \%$. Echinocandins retained their excellent in vitro susceptibility against non-albicans Candida isolates, and the overall fluconazole-resistance rate was approximately $10 \%$. More than $50 \%$ of the candidemic patients were classified as having a high risk of malnutrition, and the independent predictors of all-cause 28-day mortality were C. tropicalis, Charlson comorbidity index, Foley catheter use, concomitant bacterial infections, low platelet count, no antifungal use initially and MUST $\geq 2$.

Most recent studies have mainly analyzed the predictors of mortality in candidemic patients with secondary results regarding the incidence of septic shock, which ranged from 21.2 to $49.3 \%$ in candidemic individuals due to all Candida species [10,12,32,33], and 28.6-31.6\% among patients with non-albicans Candida bloodstream infections [33-35]. However, a much higher prevalence of septic shock (43.4\%) was observed in our study, probably because more patients with $C$. tropicalis candidemia were enrolled, which was supported by Ko et al.'s proposal [36]. Additionally, the overall fluconazole-resistance rate and in vitro susceptibility rate of echinocandins against non-albicans Candida isolates were, $3.4-8.8 \%[1,12,37]$ and $97.6-100 \%[1,37]$, respectively, comparable to our findings. Regarding the clinical outcomes, a few recent reports illustrated in-hospital mortality rates of approximately $44.6-60.0 \%$ [7,32,38], similar to our results, implicating a poor prognosis in patients with non-albicans Candida bloodstream infections. 
As previously reported, patients with fumgemia due to $C$. tropicalis might have a higher mortality rate than those with fungemia due to other Candida species [39,40]. Additionally, the significant association of $C$. tropicalis with poor clinical outcomes has been validated [36], which is consistent with our findings. Possible explanations for the virulence mechanisms of $C$. tropicalis, including its adhesion behavior, biofilm formation, hemolysis activity, secretion of enzymes, and dissemination potential [41], have been elucidated, and prominent resistance to azoles by $C$. tropicalis affecting the initiation of the appropriate antifungals might be another reason from our study. Therefore, clinicians should be aware of the care of patients with $C$. tropicalis fungemia.

Patient-related factors, such as comorbid conditions and a poor prognosis, are highly relevant among individuals with Candida bloodstream infections. Notably, the Charlson comorbidity index, a comorbidity measure useful for predicting mortality risk, has been demonstrated in several studies [11,42], comparable to our results. Likewise, indwelling urinary catheters as a risk factor for mortality among candidemic patients in our study has also been previously illustrated $[43,44]$ : predisposition to urinary tract infections and formation of biofilms on the surface of catheters lowering the efficacy of antifungals resulted in patients being more susceptible to death. Subsequently, detailed calculation of the Charlson comorbidity index and early removal of unnecessary urinary catheters would aid healthcare workers in handling the clinical outcomes of non-albicans candidemia cases.

The role of concurrent bacterial infections on in-hospital mortality in patients with candidemia has been established in previous reports [12,45], similar to our results. It was anticipated that concomitant bacterial infections would lead to candidemic patients being vulnerable to severe sepsis or septic shock and eventually increase the risk of mortality; therefore, effective antimicrobial agents against concurrent bacterial infections should be initiated aggressively to improve the clinical prognosis. Moreover, thrombocytopenia has been proposed as implicating candidemic patients with more seriously ill conditions and at high risk of mortality [46]. The adverse effects of low platelets on patients' outcomes in response to fungal infection [12] and the key role of platelets in inflammation, immunity, and infectious diseases [47] might be the causes. Nevertheless, the molecular mechanisms of thrombocytopenia and platelet function in non-albicans candidemia should be further studied. Undoubtedly, early administration and appropriate initiation of antifungal agents for fungemic patients will lead to a better prognosis $[9,48]$ than if no antifungals are initiated for these patients from the start, similar to our findings. Consequently, empirical or preemptive antifungal therapy should be considered prudently when clinicians are highly suspicious of non-albicans candidemia.

To the best of our knowledge, no previous research has explored the relationship between malnutrition and clinical outcomes in patients with non-albicans candidemia. Nutritional deficiencies are linked to a higher risk of infections and mortality from bloodstream infections [49]. A few studies have demonstrated that malnutrition predisposes acutely ill patients to acquiring infections [14], probably due to the persistent inflammation and immune dysfunction associated with undernutrition [50], and eventually, there can be progression to severe sepsis, septic shock, and death. Hence, poor nutritional status as an independent factor for all-cause 28-day mortality in patients with non-albicans candidemia is reasonable. Malnutrition is a modifiable factor: its early identification and correction among patients at high-risk might prevent its potential deleterious effects, even though there are no internationally standardized screening tools for the assessment of nutritional status [51]. MUST has been validated to predict the risk of malnutrition with the highest sensitivity and hazard ratio of mortality by Rabito et al. [27], which was similar to our results. Furthermore, non-albicans fungemic individuals within the high-risk group tended to have a higher mortality rate via the Kaplan-Meier method. Therefore, routine nutrition screening for all hospitalized patients, particularly those with non-albicans candidemia, not only predicted the risk of all-cause 28-day mortality but also established an adequate nutritional care plan tailored to these malnourished individuals to lower complication rates. 
There were some limitations to our study. First, it was conducted retrospectively; therefore, unavoidable bias and missing data are anticipated. Second, there could have been trivial variations in the collection of MUST data because this was a multicenter study, and measurement of weight loss percentage was probably a barrier during clinical practice. Finally, serum levels of some inflammatory mediators, such as interleukin-6 or interleukin-10, were not tested in our study, and how inflammatory cytokines in malnutrition patients with non-albicans candidemia played a role in the risk of mortality requires further investigation.

\section{Conclusions}

Our study revealed that a high risk of malnourishment, that is, MUST $\geq 2$, is independently associated with a higher risk of all-cause 28-day mortality in non-albicans candidemic patients. A simple and rapid screening tool for malnutrition risk, such as MUST, can help physicians recognize malnourished individuals, and early goal-directed therapy for high-risk patients can be achieved as soon as possible. Furthermore, because malnutrition remains a reversible and treatable condition, an optimal nutritional care strategy should be implemented appropriately to improve patients' prognosis.

Author Contributions: Conceptualization, Y.-C.L., F.-D.W. and W.-L.L.; methodology, Y.-C.C., J.-T.W. and W.-L.L.; validation, Y.-C.L., Y.-C.C. and W.-L.L.; formal analysis Y.-C.C. and J.-T.W.; investigation, M.-H.H., I.-M.H., Y.-L.L., M.-W.H., C.-E.L. and Y.-H.C.; resources, F.-D.W., M.-H.H., I.-M.H. and M.-W.H.; data curation, F.-D.W., Y.-L.L., C.-E.L. and Y.-H.C.; writing-original draft preparation, Y.-C.L., J.-T.W. and W.-L.L.; writing-review and editing, Y.-C.L., Y.-C.C. and W.-L.L.; visualization, J.-T.W., F.-D.W. and W.-L.L.; supervision, Y.-C.L., Y.-C.C., J.-T.W. and W.-L.L.; project administration, W.-L.L. All authors participated in the study design, revised the manuscript, and approved the final version of the manuscript. All authors have read and agreed to the published version of the manuscript.

Funding: There were no external or internal sources of specific funding for this paper, and the data were generated as part of the department's routine work.

Institutional Review Board Statement: This study was conducted based on the principles of the Declaration of Helsinki and approved by the medical ethics committees of the five participating hospitals.

Informed Consent Statement: Informed consent was not required due to the observational study design without attempting to change the standard of care.

Data Availability Statement: The datasets used during the current study are available from the corresponding author on reasonable request.

Conflicts of Interest: The authors declared no conflict of interest.

\section{References}

1. Toda, M.; Williams, S.R.; Berkow, E.L.; Farley, M.M.; Harrison, L.H.; Bonner, L.; Marceaux, K.M.; Hollick, R.; Zhang, A.Y.; Schaffner, W.; et al. Population-Based Active Surveillance for Culture-Confirmed Candidemia Four Sites, United States, 20122016. MMWR Surveill. Summ. 2019, 68, 1-15. [CrossRef] [PubMed]

2. Cleveland, A.A.; Farley, M.M.; Harrison, L.H.; Stein, B.; Hollick, R.; Lockhart, S.R.; Magill, S.S.; Derado, G.; Park, B.J.; Chiller, T.M. Changes in Incidence and Antifungal Drug Resistance in Candidemia: Results From Population-Based Laboratory Surveillance in Atlanta and Baltimore, 2008-2011. Clin. Infect. Dis. 2012, 55, 1352-1361. [CrossRef] [PubMed]

3. Bassetti, M.; Taramasso, L.; Nicco, E.; Molinari, M.P.; Mussap, M.; Viscoli, C. Epidemiology, species distribution, antifungal sus-ceptibility and outcome of nosocomial candidemia in a tertiary care hospital in Italy. PLoS ONE 2011, 6, e24198. [CrossRef] [PubMed]

4. Guinea, J.; Zaragoza, O.; Escribano, P.; Mazuelos, E.M.; Pemán, J.; Sanchez-Reus, F.; Cuenca-Estrella, M. Molecular Identification and Antifungal Susceptibility of Yeast Isolates Causing Fungemia Collected in a Population-Based Study in Spain in 2010 and 2011. Antimicrob. Agents Chemother. 2013, 58, 1529-1537. [CrossRef]

5. Tan, T.Y.; Hsu, L.Y.; Alejandria, M.M.; Chaiwarith, R.; Chinniah, T.; Chayakulkeeree, M.; Choudhury, S.; Chen, Y.H.; Shin, J.H.; Kiratisin, P.; et al. Antifungal susceptibility of invasive Candida bloodstream isolates from the Asia-Pacific region. Med. Mycol. 2016, 54, 471-477. [CrossRef]

6. Barchiesi, F.; The Candidemia Study Group; Orsetti, E.; Gesuita, R.; Skrami, E.; Manso, E. Epidemiology, clinical characteristics, and outcome of candidemia in a tertiary referral center in Italy from 2010 to 2014. Infection 2015, 44, 205-213. [CrossRef] 
7. Ghrenassia, E.; Mokart, D.; Mayaux, J.; Demoule, A.; Rezine, I.; Kerhuel, L.; Calvet, L.; De Jong, A.; Azoulay, E.; Darmon, M. Candidemia in critically ill immunocompromised patients: Report of a retrospective multicenter cohort study. Ann. Intensiv. Care 2019, 9, 1-10. [CrossRef]

8. Barchiesi, F.; Orsetti, E.; Mazzanti, S.; Trave, F.; Salvi, A.; Nitti, C.; Manso, E. Candidemia in the elderly: What does it change? PLoS ONE 2017, 12, e0176576. [CrossRef]

9. Bassetti, M.; Peghin, M.; Carnelutti, A.; Righi, E.; Merelli, M.; Ansaldi, F.; Trucchi, C.; Alicino, C.; Sartor, A.; Toniutto, P.; et al. Clinical characteristics and predictors of mortality in cirrhotic patients with candidemia and intra-abdominal candidiasis: A multicenter study. Intensiv. Care Med. 2017, 43, 509-518. [CrossRef]

10. Sbrana, F.; Sozio, E.; Bassetti, M.; Ripoli, A.; Pieralli, F.; Azzini, A.M.; Morettini, A.; Nozzoli, C.; Merelli, M.; Rizzardo, S.; et al. Independent risk factors for mortality in critically ill patients with candidemia on Italian Internal Medicine Wards. Intern. Emerg. Med. 2018, 13, 199-204. [CrossRef]

11. Luzzati, R.; Merelli, M.; Ansaldi, F.; Rosin, C.; Azzini, A.; Cavinato, S.; Brugnaro, P.; Vedovelli, C.; Cattelan, A.; Marina, B.; et al. Nosocomial candidemia in patients admitted to medicine wards compared to other wards: A multicentre study. Infection 2016, 44, 747-755. [CrossRef]

12. Jia, X.; Li, C.; Cao, J.; Wu, X.; Zhang, L. Clinical characteristics and predictors of mortality in patients with candidemia: A six-year retrospective study. Eur. J. Clin. Microbiol. Infect. Dis. 2018, 37, 1717-1724. [CrossRef] [PubMed]

13. Ngamchokwathana, C.; Chongtrakool, P.; Waesamaae, A.; Chayakulkeeree, M. Risk Factors and Outcomes of Non-albicans Candida Bloodstream Infection in Patients with Candidemia at Siriraj Hospital—Thailand's Largest National Tertiary Referral Hospital. J. Fungi 2021, 7, 269. [CrossRef] [PubMed]

14. Lew, C.C.H.; Yandell, R.; Fraser, R.J.L.; Chua, A.P.; Chong, M.F.F.; Miller, M. Association Between Malnutrition and Clinical Outcomes in the Intensive Care Unit: A Systematic Review. J. Parenter. Enter. Nutr. 2016, 41, 744-758. [CrossRef] [PubMed]

15. Sorensen, J.; Kondrup, J.; Prokopowicz, J.; Schiesser, M.; Krähenbühl, L.; Meier, R.; Liberda, M. EuroOOPS: An international, multicentre study to implement nutritional risk screening and evaluate clinical outcome. Clin. Nutr. 2008, 27, 340-349. [CrossRef] [PubMed]

16. Lew, C.C.H.; Wong, G.J.Y.; Cheung, K.P.; Chua, A.P.; Chong, M.F.F.; Miller, M. Association between Malnutrition and 28-Day Mortality and Intensive Care Length-of-Stay in the Critically ill: A Prospective Cohort Study. Nutrients 2017, 10, 10. [CrossRef]

17. Lim, S.L.; Ong, K.C.B.; Chan, Y.H.; Loke, W.C.; Ferguson, M.; Daniels, L. Malnutrition and its impact on cost of hospitalization, length of stay, readmission and 3-year mortality. Clin. Nutr. 2012, 31, 345-350. [CrossRef]

18. Piazza, O.; Boccia, M.C.; Iasiello, A.; Storti, M.P.; Tufano, R.; Triassi, M. Candidemia in Intensive Care patients. Risk factors and mortality. Minerva Anestesiol. 2004, 70, 63-69.

19. Detsky, A.S.; McLaughlin, J.R.; Baker, J.P.; Johnston, N.; Whittaker, S.; Mendelson, R.A.; Jeejeebhoy, K.N. What is subjective global assessment of nutritional status? J. Parenter. Enteral Nutr. 1987, 11, 8-13. [CrossRef] [PubMed]

20. Guigoz, Y.; Vellas, B.; Garry, P.J. Assessing the nutritional status of the elderly: The Mini Nutritional Assessment as part of the geriatric evaluation. Nutr. Rev. 1996, 54, S59-S65. [CrossRef]

21. Kondrup, J.; Rasmussen, H.H.; Hamberg, O.; Stanga, Z.; Ad Hoc ESPEN Working Group. Nutritional risk screening (NRS 2002): A new method based on an analysis of controlled clinical trials. Clin. Nutr. 2003, 22, 321-336. [CrossRef]

22. Elia, M. The 'Must' Report. Nutritional Screening for Adults: A Multidisciplinary Responsibility. Development and Use of the'Malnutrition Universal Screening Tool' (Must) for Adults; BAPEN: Redditch, UK, 2003.

23. Tang, H.-J.; Liu, W.-L.; Lin, H.-L.; Lai, C.-C. Epidemiology and Prognostic Factors of Candidemia in Cancer Patients. PLoS ONE 2014, 9, e99103. [CrossRef]

24. Chen, L.-Y.; Kuo, S.-C.; Wu, H.-S.; Yang, S.-P.; Chan, Y.-J.; Chen, L.-K.; Wang, F.-D. Associated clinical characteristics of patients with candidemia among different Candida species. J. Microbiol. Immunol. Infect. 2013, 46, 463-468. [CrossRef]

25. Wu, P.F.; Liu, W.L.; Hsieh, M.H.; Hii, I.M.; Lee, Y.L.; Lin, Y.T.; Ho, M.W.; Liu, C.E.; Chen, Y.H.; Wang, F.D. Epidemiology and antifungal susceptibility of candidemia isolates of non-albicans Candida species from cancer patients. Emerg. Microbes Infect. 2017, 6, e87. [CrossRef]

26. Clinical and Laboratory Standard Institute (CLSI). Performance Standards for Antifungal Susceptibility Testing of Yeast, 1st ed.; CLSI supplement M60; Clinical and Laboratory Standard Institute: Wayne, PA, USA, 2017.

27. Rabito, E.I.; Marcadenti, A.; Fink, J.D.S.; Figueira, L.; Silva, F.M. Nutritional Risk Screening 2002, Short Nutritional Assessment Questionnaire, Malnutrition Screening Tool, and Malnutrition Universal Screening Tool Are Good Predictors of Nutrition Risk in an Emergency Service. Nutr. Clin. Pr. 2017, 32, 526-532. [CrossRef] [PubMed]

28. Almasaudi, A.S.; McSorley, S.T.; Dolan, R.D.; Edwards, C.A.; McMillan, D.C. The relation between Malnutrition Universal Screening Tool (MUST), computed tomography-derived body composition, systemic inflammation, and clinical outcomes in patients undergoing surgery for colorectal cancer. Am. J. Clin. Nutr. 2019, 110, 1327-1334. [CrossRef] [PubMed]

29. Sremanakova, J.; Burden, S.; Kama, Y.; Gittins, M.; Lal, S.; Smith, C.J.; Hamdy, S. An Observational Cohort Study Investigating Risk of Malnutrition Using the Malnutrition Universal Screening Tool in Patients with Stroke. J. Stroke Cerebrovasc. Dis. 2019, 28, 104405. [CrossRef] [PubMed]

30. Guinea, J. Global trends in the distribution of Candida species causing candidemia. Clin. Microbiol. Infect. 2014, 20 (Suppl. 6), 5-10. [CrossRef] 
31. Kakeya, H.; Yamada, K.; Kaneko, Y.; Yanagihara, K.; Tateda, K.; Maesaki, S.; Takesue, Y.; Tomono, K.; Kadota, J.-I.; Kaku, M.; et al. National Trends in the Distribution of Candida Species Causing Candidemia in Japan from 2003 to 2014. Med. Mycol. J. 2018, 59, E19-E22. [CrossRef]

32. Ortega-Loubon, C.; Cano-Hernández, B.; Poves-Alvarez, R.; Muñoz-Moreno, M.F.; Román-García, P.; Balbás-Alvarez, S.; de la Varga-Martínez, O.; Gómez-Sánchez, E.; Gómez-Pesquera, E.; Lorenzo-López, M.; et al. The Overlooked Immune State in Candidemia: A Risk Factor for Mortality. J. Clin. Med. 2019, 8, 1512. [CrossRef]

33. Bassetti, M.; Vena, A.; Meroi, M.; Cardozo, C.; Cuervo, G.; Giacobbe, D.R.; Salavert, M.; Merino, P.; Gioia, F.; Fernández-Ruiz, M.; et al. Factors associated with the development of septic shock in patients with candidemia: A post hoc analysis from two pro-spective cohorts. Crit. Care 2020, 24, 117. [CrossRef]

34. Chen, C.-Y.; Sheng, W.-H.; Huang, S.-Y.; Chou, W.-C.; Yao, M.; Tang, J.-L.; Tsay, W.; Tien, H.-F.; Hsueh, P.-R. Clinical characteristics and treatment outcomes of patients with candidaemia due to Candida parapsilosis sensu lato species at a medical centre in Taiwan, 2000-2012. J. Antimicrob. Chemother. 2015, 70, 1531-1538. [CrossRef]

35. Puig-Asensio, M.; Padilla, B.; Garnacho-Montero, J.; Zaragoza, O.; Aguado, J.M.; Zaragoza, R.; Montejo, M.; Muñoz, P.; Ruiz-Camps, I.; Cuenca-Estrella, M.; et al. Epidemiology and predictive factors for early and late mortality in Candida bloodstream infections: A population-based surveillance in Spain. Clin. Microbiol. Infect. 2014, 20, O245-O254. [CrossRef]

36. Ko, J.-H.; Jung, D.S.; Lee, J.Y.; Kim, H.A.; Ryu, S.Y.; Jung, S.-I.; Joo, E.-J.; Cheon, S.; Kim, Y.-S.; Kim, S.-W.; et al. Poor prognosis of Candida tropicalis among non-albicans candidemia: A retrospective multicenter cohort study, Korea. Diagn. Microbiol. Infect. Dis. 2019, 95, 195-200. [CrossRef] [PubMed]

37. Khan, Z.; Ahmad, S.; Al-Sweih, N.; Mokaddas, E.; Al-Banwan, K.; Alfouzan, W.; Al-Obaid, I.; Al-Obaid, K.; Asadzadeh, M.; Jeragh, A.; et al. Changing trends in epidemiology and antifungal susceptibility patterns of six bloodstream Candida species isolates over a 12-year period in Kuwait. PLOS ONE 2019, 14, e216250. [CrossRef] [PubMed]

38. Yeşilkaya, A.; Azap, Ö.; Aydın, M.; Ok, M.A. Epidemiology, species distribution, clinical characteristics and mortality of candidaemia in a tertiary care university hospital in Turkey, 2007-2014. Mycoses 2017, 60, 433-439. [CrossRef] [PubMed]

39. Muñoz, P.; Giannella, M.; Fanciulli, C.; Guinea, J.; Valerio, M.; Rojas, L. Candida tropicalis fungaemia: Incidence, risk factors and mortality in a general hospital. Clin. Microbiol Infect. 2011, 17, 1538-1545. [CrossRef]

40. Almirante, B.; Rodríguez, D.; Park, B.J.; Cuenca-Estrella, M.; Planes, A.M.; Almela, M.; Jose, M.; Ferran, S.; Josefina, A.; Mont-serrat, G.; et al. Epidemiology and predictors of mortality in cases of Candida bloodstream infection: Results from popula-tion-based surveillance, barcelona, Spain, from 2002 to 2003. Clin. Microbiol. Infect. 2005, 43, 35-1829. [CrossRef]

41. Negri, M.; Silva, S.; Henriques, M.; Oliveira, R. Insights into Candida tropicalis nosocomial infections and virulence factors. Eur. J. Clin. Microbiol. Infect. Dis. 2011, 31, 1399-1412. [CrossRef]

42. Vaquero-Herrero, M.P.; Ragozzino, S.; Castaño-Romero, F.; Siller-Ruiz, M.; González, R.S.; García-Sánchez, J.E.; García-García, I.; Marcos, M.; La Vega, H.G.T.-D. The Pitt Bacteremia Score, Charlson Comorbidity Index and Chronic Disease Score are useful tools for the prediction of mortality in patients with Candida bloodstream infection. Mycoses 2017, 60, 676-685. [CrossRef]

43. Tumbarello, M.; Fiori, B.; Trecarichi, E.; Posteraro, P.; Losito, A.R.; De Luca, A.; Sanguinetti, M.; Fadda, G.; Cauda, R.; Posteraro, B. Risk Factors and Outcomes of Candidemia Caused by Biofilm-Forming Isolates in a Tertiary Care Hospital. PLoS ONE 2012, 7, e33705. [CrossRef]

44. Da Silva, R.B.; Neves, R.P.; Hinrichsen, S.L.; de Lima-Neto, R.G. Candidemia in a public hospital in Northeastern Brazil: Epi-demiological features and risk factors in critically ill patients. Rev. Iberoam. Micol. 2019, 36, 181-185. [CrossRef]

45. Muderris, T.; Kaya, S.; Ormen, B.; Gokmen, A.A.; Akpinar, C.V.; Gul, S.Y. Mortality and risk factor analysis for Candida blood stream infection: A three-year retrospective study. J. Mycol. Med. 2020, 30, 101008. [CrossRef] [PubMed]

46. Zhang, W.; Song, X.; Wu, H.; Zheng, R. Epidemiology, risk factors and outcomes of Candida albicans vs. non- albicans candi-daemia in adult patients in Northeast China. Epidemiol. Infect. 2019, 147, e277. [CrossRef] [PubMed]

47. Zhang, W.; Song, X.; Wu, H.; Zheng, R. Epidemiology, species distribution, and predictive factors for mortality of candidemia in adult surgical patients. BMC Infect. Dis. 2020, 20, 506. [CrossRef]

48. Poves-Alvarez, R.; Cano-Hernández, B.; Muñoz-Moreno, M.F.; Balbás-Alvarez, S.; Román-García, P.; Gómez-Sánchez, E.; Martínez-Rafael, B.; Gómez-Pesquera, E.; Lorenzo-López, M.; Alvarez-Fuente, E.; et al. Impact of empirical treatment with antifungal agents on survival of patients with candidemia. Rev. Esp. Quim. Publ. Soc. Esp. Quim. 2019, 32, 6-14.

49. Martinez, R.M.; Wolk, D.M. Bloodstream Infections. Microbiol. Spectr. 2016, 4, 4. [CrossRef]

50. Nomellini, V.; Kaplan, L.J.; Sims, C.A.; Caldwell, C. Chronic Critical Illness and Persistent Inflammation: What can we Learn from the Elderly, Injured, Septic, and Malnourished? Shock 2018, 49, 4-14. [CrossRef]

51. Reber, E.; Gomes, F.; Vasiloglou, M.F.; Schuetz, P.; Stanga, Z. Nutritional Risk Screening and Assessment. J. Clin. Med. 2019, 8, 1065. [CrossRef] [PubMed] 